\title{
Creating Innovation Policies that Leads to Positive Future Spillovers - A Critical Review
}

\author{
Mohamed Buheji \\ Founder of the International Inspiration, Economy Project, Bahrain \\ E-mail: buhejim@gmail.com
}

Received: January 8, 2020 Accepted: January 17, 2020 Published: January 21, 2020

doi:10.5296/ber.v10i1.16308ＵRL: https://doi.org/10.5296/ber.v10i1.16308

\begin{abstract}
This paper reviews what is the essence and importance of innovation policy today and in the future. The Importance of innovation meta-analysis and its benefits for the policies beneficiaries and stakeholders are explored. Then, cases of market failure and how innovation policies could bring influence and spillovers on the economy, are discussed.

This critical review implies that it shows the main mechanisms of innovation instruments and where the essentials and the rationales of creating socially preferable innovation policies need to be more investigated as per the clusters targeted for competitiveness differentiation.
\end{abstract}

Keywords: Innovation Policy Impact, Economic Spillovers, Future Foresight, Competitiveness

\section{Introduction}

Innovation and competitiveness have been strong companions since their inception. See any country that differentiated its self with innovation, and you see that its competitiveness is very hard to copy. The researcher became interested in innovation policies influence as it addresses crucial socio-economic challenges, and its spillovers on the foresighted future need more synthesis, Edler and Fagerberg (2017).

Innovation policies support the generation of the innovative process, and define its diffusion, adoption. It is only through these policies we can ensure the novelties of all the innovative processes and initiatives. Therefore, this paper targets to create a contribution towards more focused approaches that link the impact of the innovation policies set today on the mechanism for future foresight and to create more positive spillovers in the future. 


\section{Critical Review}

\subsection{What is Innovation Policy, and Why it is Important?}

Studying the innovation policies designs perspectives for the future is highly essential for innovation policymaking and its type of instruments. Without understanding the impact of innovation input and output we cannot plan adequately for any country's competitiveness and foresighted future, as you might plan for the future, but your policies could keep you in the hurdle, chained.

In this critical review of innovation policies, we would focus on the Edler et al., (2016) handbook that brings in the conceptualisation of innovation policies with typology, supported by meta-evaluations for crucial innovation policy instruments and analysis evidence on policy-mix, Buheji (2018).

Previous studies have mainly focused on specific policies, programmes and projects to assess their past performance and, in some cases, to improve a country's, or cluster, future design and implementation. Such contributions bring a systematic analysis of secondary evidence on the impact of interventions in innovation policy. Such analyses are found in the areas of education, health and international development amongst others.

\subsection{The Importance of Meta-analysis of the Innovation Theory Diffusion While Setting the Innovation Policy}

A meta-analysis of the innovation policies impact is usually done based on the primary data from different studies that are pooled and analysed, improving robustness and validity. The idiosyncrasies of policy-interventions, requires dealing with uneven data availabilities. Most of the existing evidence and analysis are based on individual policies, Elder et al. (2016).

Innovation policy depends on the level of interventions designed and the type of the innovation theory or the approach used. Usually, such policies are administered by the government, or semi-governmental organisations. In certain countries, such policies are deployed by a consortium of multiple agencies at various spatial levels. Studies show that larger firms or developed countries will produce fewer innovations per dollar spent on R\&D, but their innovations will be on average of higher quality, Elder et al., (2016).

Innovation diffusion plays an essential part of innovation analysis. This means that in order for a realised innovation improvement to happen we need to dissect and then plan how ideas, processes and products can diffuse in the community targeted, be it organisation, or a sector, or a society, or a country.

The generation of innovation involves the production of underlying knowledge, artefacts and practices that are needed to produce something novel. Thus, innovation policy spillover to the area of science, research and technology and influence their policies effectiveness, Buheji (2018).

\subsection{Specifying Innovation Policies Beneficiaries and Stakeholders}

The target groups of innovation policies are, in principle, all those actors who generate 
innovations from the supply side and also those who ask for, absorb and use innovations from the demand side. Edler et al. (2016).

In reality, these innovation policies balance the equality required for raising the capacity in relevance to the demand needed for the contemporary competitiveness and survival, or the future foresighted differentiations for any country or organisation. Therefore, any stakeholder in the supply chain, be it towards the supply, or the demand can be affected by the locus of the design and implementation of innovation policy.

The main idea of innovation policy is to bring the capacities, the capabilities, the changeability and the competencies together for the benefit for the production of knowledge and its related innovation from both the producers and the users. Buheji (2018).

The stakeholders of innovation policy can extend to the critical government ministries or agencies as education, electricity and water authorities, healthcare, transportation and even ministries concerned with the socio-economic development. Such government entities could make a differentiation to the total innovation impact in the country and serve in the diffusion of innovative solutions and thus address it is the demands for it. Elder et al. (2016).

\subsection{Innovation Policies in Cases of Market Failure}

Innovation can make an excellent differentiation for market equilibrium. Innovation policies also could intervene even in case of market failures as they could work on influencing knowledge generation that would lead to equalising the market again.

Innovation policies, therefore, could help to enhance the production of knowledge in public organisations, besides support speeding up start-up initiatives. In the presence of innovative culture, even intellectual property. Such respect for rights helps to exploit the optimum knowledge production.

Innovation-market failures can occur at different points. It could occur on the supply side, during the generation of the basic knowledge, or on the demand side, during the possibilities of learning by early adoption, and finally at the interface of both the supply and demand where information asymmetries could occur. Such information asymmetries, could also lead to hampering investment in both innovation generation and the capacity for innovation absorption.

\subsection{Innovation Policies Influence on Economy}

Innovation has its roots in evolutionary economics. Innovation has an interplay in system components, whereby the generation of knowledge and innovation is characterised by constant interaction and learning.

Innovation policy found to intervene with any system functions that do not perform to a level regarded as sufficient. With innovation presence analysis of the problems depends on levels where to which innovation could intervene, Elder et al., (2016).

The amount of any economic development depends not only the innovation policies framework, but rather more in its existing legal and regulatory conditions, besides its 
financial support. These conditions would define not the level of how much innovation could be generated and diffused; but rather the adequacy of innovation in any system and its sufficient future exchange.

Production of innovation (on the supply side) and on the demand side as well (e.g. ability and willingness to adopt an innovation) defines the level of cooperation with the economic market players. The economic rationale for innovation is based on the idea that science and innovation can contribute to addressing socio-economic missions and challenges, Edler and Fagerberg (2017).

To illustrate the importance of innovation policy on the economy, Elder et al., (2016) mentioned the USA specific policy objectives and the way it is designed and implemented. The departments responsible for innovation policy deployment in the USA focus on the horizontal diffusion of the innovation policies across the different infrastructures.

\subsection{Creating Socially Preferably Innovation Policies}

In order to create socially preferable policies, we require innovative policies that lead to technological development in the areas of both state and citizen needs. This means we need both to innovate areas similar to healthcare, education and commerce where the citizen and the government could optimise to the benefit of the society development.

Social change comes when there are a set of attempts by the different stakeholders, including the government authorities that optimise the information and use it to develop the absorptive capacity to a specific goal. In innovation, this change can start by identifying the gap, and understanding the social and socio-economic cause, and then design the appropriate instruments that lead to this achievement, Edler and Fagerberg (2017).

\subsection{General Rationales for Innovation Policy}

Policy interventions depend on decisions where instruments could be employed to steer innovation. The level of understanding or realising how innovation could be diagnosed, or could be used as a therapy controls its complexity.

The rationale of innovation systems and processes is that they help to deliver complex and idiosyncratic processes. Innovation policies help to develop bounded rationalities that could comprehensively contextualise the innovation instruments.

\subsection{Mechanisms of Innovation Instruments}

Innovation needs specific instruments that can be selected and implemented to solve a given problem; Buheji and Ahmed (2018). The impact of an instrument can be defined as per the change that it could create on the socio-economy, or the wholly, or partially attributed to change.

Instruments can be emphasised by organisations that enforce and push towards practical actions that are actively constructed. These instruments can be dynamic and could play a differentiated role in both the social and the interactive process. These instruments could be redefined to with each application, and also adjusted according to contexts and over time, 
Elder et al., (2016).

The level of how these instruments are designed and implemented depends on the collective efforts of the instrument owners, i.e. the government organ9satino and the other sponsoring agents, besides the universities. A critical appraisal of the instrument mechanisms found to improve their transferability and impact, besides lead to spillovers.

\subsection{Classification of Innovation Policy Instruments}

One of the first challenges in compiling a synthesis of evidence on innovation policy is to organise the evidence-based into manageable, logical classifications that are appropriate to the analytical purpose they are intended to serve.

All the innovation instruments should be evaluated based on their capacity for increasing the research and development outcome, Buheji and Ahmed (2018). Evidence on the impact and spillovers of the innovation instruments can come from both financial and non-financial capabilities that the policies for training and skills delivery.

Other innovation instruments might come from the entrepreneurship policies and clusters that the country set in specific sectors or industries. The other type of innovation instrument is the technical services and counselling available to those need, work with or lead innovation. Therefore, innovation needs cluster-based policies and policies that support innovation and collaboration networks, Elder et al., (2016).

Many leading developed countries, are developing future innovation instruments that could enhance the capacity vs the future expected demands for innovation. Therefore, one could experience that the private sector demands for innovation are stimulated more than ever today in innovation awards and prizes.

One of the critical coming innovation instruments is the focus on foresight future technology. This foresight focuses on the design approaches that define the type of innovation policies that creates a balance between communication, besides supply and demand, Edler and Fagerberg (2017).

The last instrument of innovation focuses on policy mixes which focus on understanding the interplay of instruments, both for attempts to deliberately design and coordinate a mix of instruments. Such mixes bring in policies for training and skills, besides entrepreneurship policies that lead to cluster development.

\section{Conclusion}

This paper is built on the analysis and the critical review of the current literature on innovation policy with a focus on the Elgar Handbook of Innovation Policy Impact, by Elder et al., (2016). The research explores what needs to be focused on for the future of innovation policies, taking into consideration the impact of innovation in the last few decades.

The link between the innovation policies impact found to influence the mechanism for future foresight and the possibilities for positive innovation spillovers. Therefore, the research emphasises the importance of specifying the innovation policies beneficiaries and 
stakeholders and the learning from the cases of market failure. This work also illustrates the importance of designing socially preferable innovation policies, and then goes more in-depth into touching base on the innovation instruments mechanisms.

Since innovation is the outcome of the innovation policies available in the organisation and country, and they are the key to the challenges that arise any idea or process or product; this paper opens more debate, in the knowledge community, about how such policies should be fostered in the future to develop these three factors; i.e. the ideas, the processes and the products. The work of Elder et al. (2016) is an excellent reference for innovation clusters planners and any economic severe development board or entity; however it needs to be taken with its limitations when it comes in relevant to the details of innovation diffusion and the type of innovation policies applicable to different countries, or sectors, or clusters. This paper raises a clear gap in the literature about investigating the rationales behind an innovation policy and then how it should be designed, implemented, and governed. It is a good start for innovation researchers to study the work of Elder et al. (2016) and most important to develop future pathways that such policies need to meet both the technological and socio-economic demands of the future.

\section{References}

Buheji, M. (2018). Book Review-Handbook of Innovation and Standards. Business and Management Studies, 4(1). https://doi.org/10.11114/bms.v4i1.2977

Buheji, M., \& Ahmed, D. (2018). Book Review - Capturing the Innovation Opportunity Space Creating Business Models with New Forms of Innovation. International Journal of Inspiration \& Resilience Economy, 2(1), 30-30.

Buheji, M. (2012). Seeds on the Road of Competitiveness. Muntada Almaref, Lebanon. (in Arabic).

Edler, J., Cunningham, P., Gök, A., \& Shapira, P. (2016). Handbook of Innovation Policy Impact. E-Elgar, USA. https://doi.org/10.4337/9781784711856

Edler, J., \& Fagerberg, J. (2017). Innovation policy: what, why, and how. Oxford Review of Economic Policy, 33(1), 2-23. https://doi.org/10.1093/oxrep/grx001

\section{Copyright Disclaimer}

Copyright for this article is retained by the author(s), with first publication rights granted to the journal.

This is an open-access article distributed under the terms and conditions of the Creative Commons Attribution license (http://creativecommons.org/licenses/by/3.0/). 